DOI: https://doi.org/10.29166/tyc.v1i19.2077

\title{
Movilidades y poder en el sur del Ecuador, 1950-1990
}

\section{María Mercedes Eguiguren • 2019}

\author{
Quito: Editorial FLACSO • 292 páginas
}

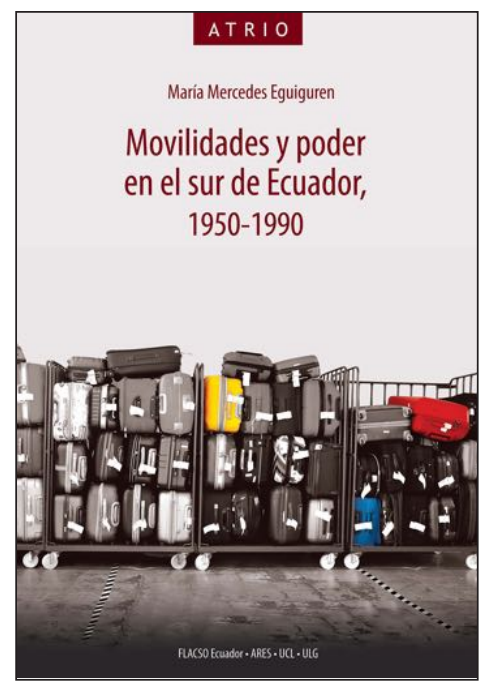

La Sierra sur del Ecuador tiene una antigua historia vinculada con las migraciones. Su población ha emprendido proyectos de movilidad tanto dentro del país como hacia el exterior desde hace varias décadas. Algunos de estos movimientos tienen relación con el lugar que ha ocupado esta región geográfica en los procesos de desarrollo impulsados por el Estado. Otros proyectos migratorios surgen más bien del ámbito de la subjetividad, es decir, son impulsados por expectativas y anhelos de orden personal. María Mercedes Eguiguren presenta una obra en la que entrecruza todos estos elementos para estudiar la migración desde las provincias de Cañar y Loja, en la Sierra sur ecuatoriana, a lo largo de cuatro décadas.

Una característica destacada de su obra es que incorpora la dimensión histórica al análisis. Lo hace al presentar una cuidadosa panorámica en la que observa, por una parte, la configuración del espacio de Cañar y Loja en el proyecto estatal nacional y, por la otra, las tendencias migratorias que se suscitaban en dichos territorios. Su reflexión apunta a que algunas de dichas tendencias surgen como respuesta al lugar periférico asignado por el Estado a ambas provincias ecuatorianas.

Para comprender el tema de la configuración del espacio, la autora se remonta a las primeras décadas de la República. Se refiere a algunos circuitos comerciales vigentes desde los inicios de la vida republicana del país mediante los cuales, productores del sur del Ecuador forjaron relaciones perdurables, por ejemplo, con el Perú. Repasa el proyecto civilizatorio de inicios del siglo XX y propone comprender cómo en este contexto se estableció una jerarquía espacial a partir de dos ejes: el primero, "la tecnología moderna (el ferrocarril), y el segundo, el ordenamiento espacial de delimitación de lo urbano y lo rural" (Eguiguren 2019, 68). Se detiene posteriormente en los proyectos de desarrollo y administración del territorio en la segunda mitad del siglo XX.

La autora señala cómo, entre estas políticas, la reforma agraria y la colonización buscaron incidir directamente sobre la movilidad de la población con el objetivo de modificar la distribución poblacional en el territorio del país. El rol de CREA (Centro de Recuperación Económica de Azuay y Cañar) a finales de la década del 60 y PREDESUR (Programa Regional para el Desarrollo del Sur) en la década del 80 también es abordado en el análisis de la configuración del espacio. Este tema se cierra con una mirada a los debates que se suscitan en la década del 90 en torno a la descentralización. 
Una vez establecido el marco de la configuración del espacio, el libro presenta un capítulo sobre los circuitos migratorios en espacios periféricos. En este segmento aparecen ya las voces de la gente que protagonizó diversos desplazamientos en búsqueda de alternativas a las estructuras económicas y sociales dominantes.

Conocemos, entonces, a Luis, finquero cañarejo de 76 años que nació en Gualleturo pero se estableció posteriormente en Ducur, ambos poblados de las tierras bajas de Cañar; a Galo, emigrante lojano quien se asentó en 1963 en (lo que entonces se llamaba) Santo Domingo de los Colorados; a Telmo, un campesino oriundo de Cañar que trabajó durante mucho tiempo en Guayaquil; a Elena, lojana que se estableció en Newark, Estados Unidos, a principios de los años 70, para luego volver a su ciudad natal.

El libro recoge sus testimonios y los de muchas otras personas cuyas vidas estuvieron marcadas por la migración. Eguiguren realizó 80 entrevistas entre los años 2013 y 2014 en once lugares en Ecuador, entre ellos Biblián, La Troncal o Cariamanga, y nueve localidades en Estados Unidos, incluyendo Manhattan, Boston o Milford, en el estado de Massachussets. La presencia de diversos relatos de migrantes permite atisbar en las variadas maneras en que ellas y ellos concibieron y ejecutaron sus proyectos de movilidad. Estos pasajes enriquecen la lectura y sustentan algunos de los planteamientos centrales del libro. Uno de ellos propone cómo, quienes migran no necesariamente están manifestando oposición a los proyectos estatales de desarrollo, sino que "han negociado un lugar diferente a aquél que les es atribuido a partir de una pertenencia territorial periférica" (Eguiguren 2019, 168).

En su capítulo final, sobre modernidad periférica y cambio generacional, Eguiguren vuelve a mirar las distintas trayectorias de migración con énfasis en las generaciones. Observa cómo muchas de las personas migrantes nacidas entre 1930 y 1950 lo hicieron en pos de la propiedad de la tierra. Destaca cómo en la generación nacida entre 1951 y 1970, la migración fue motivada por aspiraciones como alcanzar una mejor educación o por la posibilidad de consolidar vínculos transnacionales ya existentes. Concluye con una reflexión sobre las personas nacidas en las tres últimas décadas del siglo XX. Ellas y ellos, según muestra la autora, manejan un mayor abanico de posibilidades para construir un proyecto propio, con lo cual se vislumbra una generación que, de alguna manera, logra enfrentar al régimen neoliberal.

En el campo de estudios de las migraciones, la obra de María Mercedes Eguiguren ofrece un análisis profundo con valiosos aportes. El primero es incorporar Loja a su investigación, pues esta provincia del sur del Ecuador ha sido poco estudiada. El segundo es su perspectiva histórica, que abarca una mirada a la configuración del territorio desde inicios de la República hasta la actualidad, así como los testimonios de personas migrantes de tres generaciones. Y el tercero es su enfoque, centrado en el vasto y revelador ámbito de las subjetividades.

Nadesha Montalvo Rueda

Correo: nimontalvo@flacso.edu.ec 